\title{
The Theoretical Logic and Implementation Path of Constructing the New Development Pattern of "Double Circulation" from the Perspective of Political Economy
}

\author{
Wenlong Shi \\ Chongqing Vocational College of Business and Industry, Chongqing, China \\ Email: 1016156410@qq.com
}

How to cite this paper: Shi, W. L. (2021). The Theoretical Logic and Implementation Path of Constructing the New Development Pattern of "Double Circulation" from the Perspective of Political Economy. Open Journal of Social Sciences, 9, 29-39.

https://doi.org/10.4236/jss.2021.98003

Received: July 6, 2021

Accepted: July 31, 2021

Published: August 3, 2021

Copyright (c) 2021 by author(s) and Scientific Research Publishing Inc. This work is licensed under the Creative Commons Attribution-NonCommercial International License (CC BY-NC 4.0). http://creativecommons.org/licenses/by-nc/4.0/

\begin{abstract}
This paper based on the theory of marxist political economics "binary" thought, puts forward total contradiction movement in the process of social production is a new development pattern of "binary" theoretical basis, establishes a new development pattern of "binary" rely on "factor market", "product marketing", and needs to make full use of the domestic market on the basis of expanding the international market "market space". At the same time, it definitely points out that "efficient market" and "efficient government" are the fundamental guarantee of the new development pattern of "double circulation". The constraint conditions of constructing the new development pattern of "double circulation" are analyzed from four dimensions: economic system, innovation ability of market subjects, regional location and industrial structure. Finally, according to the realistic constraints of constructing the new development pattern of "double circulation", the paper puts forward the concrete implementation path: in the top-level design of the economic system, the market should play a decisive role in the allocation of resources, and the government should play a greater role; in the aspect of cultivating the innovation ability of market subjects, we should implement the innovation-driven strategy and promote comprehensive innovation with scientific and technological innovation as the core. In terms of regional and regional cooperation and development, we will coordinate regional development internally and integrate into the global economy in an all-round way externally. At the level of industrial structure optimization and upgrading, efforts should be made to optimize the supply-side structural reform and strive to achieve a benign interaction between supply and demand.
\end{abstract}




\section{Keywords}

Political Economy, "Double Circulation” New Development Pattern, Theoretical Logic, Implementation Path

\section{Introduction}

Economic globalization has become an inevitable trend of socialized development of production. After more than 40 years of reform and opening up, China's economy has achieved sustained and rapid development, and China's status in the world economic pattern has been significantly enhanced. In 1978, China's GDP was less than 150 billion US dollars, accounting for only $1.7 \%$ of the world's total economy. Although affected by COVID-19 epidemic in 2020, China's GDP still reached 14.9 trillion US dollars, accounting for $17.7 \%$ of the world's total economy. China has been the world's second largest economy for 10 years in a row. In recent years, profound and complex changes have taken place in the domestic and international environment in which China's economic development is facing. In terms of the international environment, with the rise of antiglobalization, the international governance system is facing a crisis, the global economy is growing slowly, the world economy is still under great pressure to recover, and the external economic environment is grim. On the domestic environment, new changes have taken place in the principal contradiction facing Chinese society, and China has entered a crucial period of tackling problems such as changing the growth model, improving the economic structure and changing the drivers of growth. It has become an important task for us to promote changes in the quality, efficiency and driving force of economic development and increase total factor productivity in building a modernized economic system and realizing the transition from the previous stage of rapid growth to a stage of high-quality development. How to respond to the complex changes in the international environment, seize the important period of strategic opportunities, and make active choices that adapt to the characteristics of China's economic development stage? Chinese President Xi Jinping has proposed to "accelerate the construction of a new development pattern featuring domestic cycles as the mainstay and mutually reinforcing domestic and international cycles." Build "binary" new development pattern is the Chinese government put forward in time according to the domestic and international situation of the development of the new change of major strategic deployment ${ }^{1}$. The proposal and practice of the new development pattern of "double circulation" is the internal requirement of the evolution of major contradictions at home and abroad (Wang \& Qi, 2021), and it is a strategic provision for China's future development path through the interpretation and emphasis of the economic system cycle (Wu, 2020). Based on ${ }^{1}$ Cited from the website of Economic Daily News (http://theory.people.com.cn/n1/2020/0715/c40531-31783726.html)_ “Accelerate the building of a new pattern of development in which the two cycles reinforce each other.". 
the perspective of Marxist political economy, this paper studies the theoretical logic and concrete realization path of the new development pattern of "double circulation".

The research structure of this paper is as follows: Firstly, in the introduction part, it puts forward the international background and the domestic background that China is facing when speeding up the construction of the new development pattern of "double circulation"; Secondly, it elaborates the thought of "double circulation" in Marxist political economy theory, so as to lay a theoretical foundation for the study of the new development pattern of "double circulation". Finally, this paper puts forward the implementation path of constructing the new development pattern of "double circulation".

\section{The "Double Circulation" Thought in Marxist Political Economy Theory}

The thought of "double circulation" advocates that the factors of production and commodities should break through the boundaries of countries and regions and deepen the economic exchanges and cooperation between different countries. In this way, resources can be better distributed on a global scale. The new development pattern of "double circulation" is put forward to solve the problem of the obstruction of production, distribution, exchange and consumption in China's economic and social relations, and its theoretical source is the world market theory in Marx's political economy research system. Although in classic theory of Marx and Engels did not directly in this paper, the theory of "binary" new development pattern, but they are about the process of social production total contradiction movement theory, the law of value principle, resource allocation methods, economic liberalization and globalization theory to build the "binary" new pattern of development laid a solid theoretical foundation, The above Marxist political economy theory provides important inspiration and thinking for us to construct the new development pattern of "double circulation".

\subsection{The Theoretical Basis of the New Development Pattern of "Double Circulation"-The Contradictory Movement in the Total Process of Social Production}

The great economic cycle of a country is the effective transformation of each link of economic operation and the orderly operation of the whole national economy (Wang \& Niu, 2021). From total contradiction movement in the process of social production, the production, distribution, exchange and consumption constitute the total social production process, the realization of the rights of the four links of internal self-consistent and orderly development, directly linked to the economic cycle can be smooth, four links for social production process, production is the starting point, as Marx in the "preface to a contribution to the to the critique of political economy, "The object before us is, above all, material creation." The domestic economic cycle has both a positive cycle with productivity as the starting point and consumption as the end point, and a reverse cycle with con- 
sumption as the starting point and output as the end point (Lin, 2021). Allocation and exchange are the intermediate link that connects production and consumption. The new development pattern of "double circulation" seems to be aimed at the layout of circulation and distribution links, and the purpose of circulation is to realize multiplication (Wang \& Qi, 2021). However, only when sufficient value is created in the output link, can the exchange in the next link be realized, and then the consumption in the final link be completed. Marx's theory of contradictory movements in the total process of social production, specifically his emphasis on the decisive role of the production link and his dialectical analysis of the dynamic and reactive effect of consumption on production, provide a theoretical basis for us to construct a new pattern of development.

\subsection{The Practical Support of the New Development Pattern of "Double Circulation"-_Factor Market" and "Product Market"}

Marx believed that labor force, capital, technology and other interaction, together constitute an important driving factor to promote economic development. To understand the double circulation from the perspective of political economy, the focus is to break the links of production, circulation, consumption and distribution at home and abroad (Cheng \& Zhang, 2021). Build in a large domestic cycle as the main body, domestic and international binary mutual promotion of the new development pattern is the key to dismantle the restriction of the national economy quality loop "fence", through different economies in the factor market, product market the "point", between the connection between different economies in the factor market, product market "break point". The factor market can provide a steady stream of driving factors, such as labor force, capital, land, technology, information and other essential elements of modern production, for the sustainable development of the economic cycle and for ensuring continuous and uninterrupted production and meeting the market consumption demand. It is in the product market that the products produced enter the final consumption link, and the value and use value of the goods are realized in the product market. The distribution, exchange and consumption in the total process of social production cannot be separated from the product market. To construct the new development pattern of "double circulation", the connotation of "cycle" here is vibrant, and the author thinks that the realization of the benign big cycle of factor market and product market is the key point of the topic. Therefore, from the perspective of input and output, "factor market" and "product market" are the real support to construct the new development pattern of "double circulation". (As shown in Figure 1).

\subsection{Market Space of the New Development Pattern of "Double Circulation"- "Domestic Market" and "International Market"}

Marxism believes that human society will eventually move from the history of various nations to the history of the world, and that economic globalization is an important material basis for the development of world history. The division of 


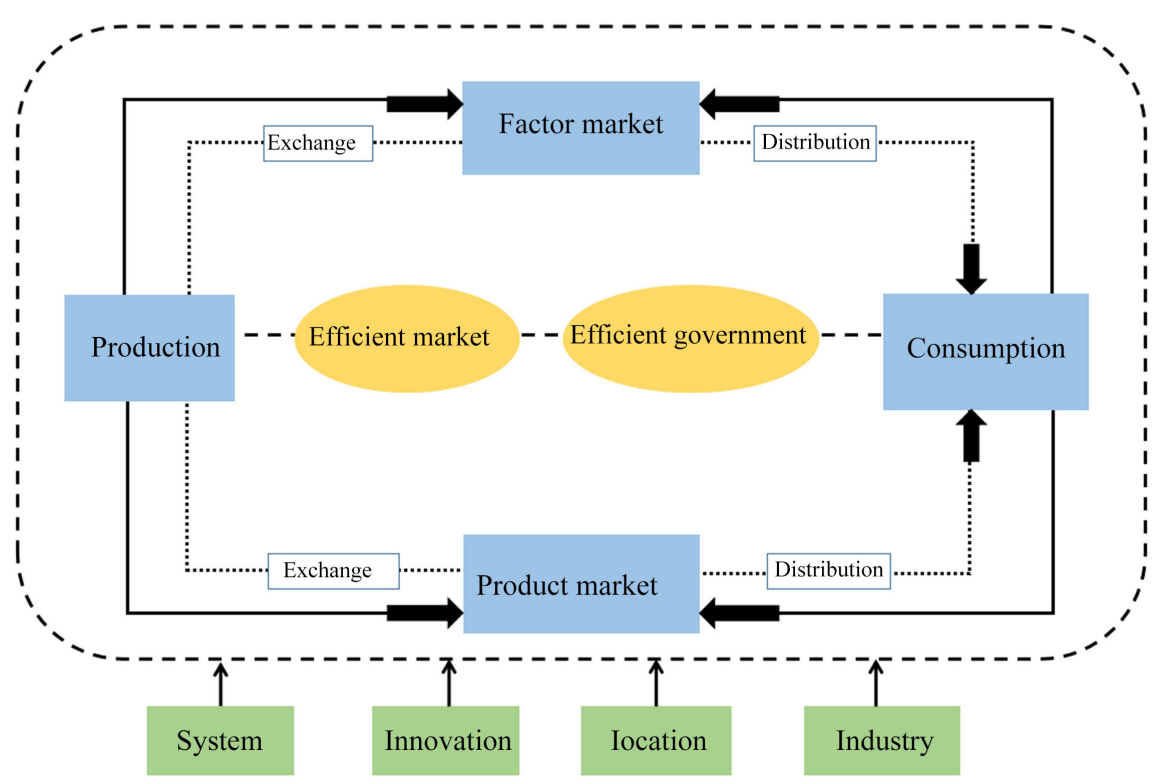

Figure 1. "Double circulation" economy development chart.

the domestic market and international market not only because of the geography space difference, it is established on the basis of the international division of labor and exchange of the inevitable requirement of modern economic development, the international market is an extension of the domestic market, can say is based on the domestic market, actively participate in, into the international market is the history of the development of economic globalization trend. From the relationship between domestic cycle and domestic and international double circulation, the domestic cycle is the foundation. The domestic cycle provides a solid foundation for the domestic and international double circulation. The global cycle plays an auxiliary role. The domestic cycle is the main body. The world cycle has played a promoting role. With a population of 1.4 billion, China has a immense scale products consumer market advantages, broad market space can provide development opportunities for all countries in the world, at the same time, build the "binary" introduced new development pattern is conducive to China's commodities in different countries around the world, in the factor market to actively use factors of production in countries around the world, Capable of reallocating resources through international division of labor and market exchange.

\subsection{The Fundamental Guarantee of the New Development Pattern of "Double Circulation"-_Efficient Market" and "Efficient Government"}

The new development pattern of "double circulation" is actually a combination of a series of market exchanges implemented in factor market and product market. This kind of market exchange cannot be separated from effective market order and promising government. The effective market order and the government's active and effective macro-control are the fundamental guarantee to con- 
struct the new development pattern of "double circulation". On the one hand, in the modern market economy, only the market can allocate the limited resources to a place that can play the best role by means of distribution and exchange. Law of value plays an irreplaceable role in the market, the law of value is the important foundation of market mechanism to play its function, in the real economic life, whether it is in the international market, the domestic market, or the factor market, product market, value law adopted market mechanism to play a role, law of value through the market mechanism to stimulate technological innovation commodity producers, Improve labor productivity, thereby promoting the development of the productive forces of the whole society. On the other hand, the construction of the new development pattern of "double circulation" cannot be separated from an active and promising government. In order to overcome the spontaneity, blindness and lag in the "double circulation" market, an active and promising government is needed, and the benign cycle of the market requires scientific and reasonable economic system arrangement and policy design. At the same time, between different economies in the world for the government to play a leading role in economic development, to grasp the law of market value principle on the basis of according to oneself characteristic, strengthen macroeconomic policy coordination, reduce or even eliminate the trade barriers between different economies, to improve the degree of trade liberalization, the deepening global economic cooperation, to create more favorable conditions ${ }^{2}$.

\subsection{Constraint Conditions of the New Development Pattern of "Double Circulation"-_Soft Constraint" and "Hard Constraint"}

The principle of unity of productive forces and relations of production, economic base and superstructure is an important theory of Marxist political economy. When the relationship of productivity ADAPTS to the productive forces and the superstructure ADAPTS to the economic base, it will considerably promote the development of social productive forces. The core content of the new development pattern of "double circulations" is that the domestic cycle is the main body and the domestic and international double circulations promote each other. In order to realize the mutual promotion of domestic and international double circulations, it is necessary to clarify the realistic constraint conditions of the new development pattern of "double circulations". Among them, the economic system and the innovation ability of market subjects belong to the "soft constraints", while the geographical location and industrial structure belong to the "hard constraints". The economic system belongs to the content of the superstructure, and marketization is the core of the economic system. The higher the degree of marketization, the wider the degree of participation in the international division of labor, and the more able it will be to promote the development

${ }^{2}$ Zhang Yu, Xie D, Ren Baoping, Jiang Yongmu, Political Economy of Socialism with Chinese Characteristics, Higher Education Press, 2021, p. 297. 
of economic globalization toward a more open, inclusive, mutually beneficial and win-win direction. Market entities with good innovation ability can adapt to the great cycle and directly upgrade the efficiency of the national economic cycle. Geographical location is an important factor affecting the "double circulation". The virtuous cycle itself has special attributes. Different economies have different geographical location conditions, and such geographical location differences will directly affect the realization of the cycle. For various economies, the difference in industrial structure directly determines their position in the circular economy. The better the industrial foundation and the sound industrial organizational structure system, the more conducive to the circular development of economy.

\section{The Implementation Path of the New Development Pattern of "Double Circulations"}

\subsection{The Top-Level Design of the Economic System: Let the Market Play a Decisive Role in the Allocation of Resources, and Give Better Play to the Role of the Government}

Economic system as an important part of the superstructure, doing a good job in the top-level design of economic system level, advancing with The Times and improving the supporting reform measures in the field of economic system, can stabilize the economic foundation of a country, considerably stimulate the development of social productivity. On the one hand, the key to building a new development pattern of "double circulations" is to let the market play a decisive role in resource allocation. "Binary" new development pattern of construction and mutual supporting high standards of market system, the basic requirement of the market system standard is to respect the law of value, both in the domestic market and international market, or the production factor market, product market, must be the law of value in competition by price, supply and demand, regulating and controlling the flow of factors of production, adjust the social production, To enable the best allocation of resources in the world. On the other hand, it is necessary to give full play to the active role of the government in economic development to construct the new development pattern of "double circulation". The Chinese government should take the initiative to adapt to the new trend of economic globalization, form an open economic system, and promote the orderly and free flow of factors in both the international and domestic markets. At the same time combined with the domestic market development of new dynamic, active and effective implementation of macroeconomic regulation and control policy, establish and upgrade the domestic factor market, domestic products market access mechanism, enhance the elements of market operation mechanism, promote the land, labor, capital, technology, data elements such as marketoriented reform, continue to strengthen antitrust and against unfair competition law enforcement and judicial, We will improve our ability to comprehensively regulate the market. 


\subsection{Cultivation of Innovation Ability of Market Entities: Implement Innovation-Driven Strategy and Promote Comprehensive Innovation with Scientific and Technological Innovation as the Core}

Whether it is to realize the great cycle at home or to promote the great cycle at home, it cannot be separated from the innovation ability of the market subjects, and the construction of the new development pattern of "double circulation" puts forward higher requirements for the innovation ability of the market subjects. This requires that based on social production, focus on product market consumption, fully implement the innovation-driven strategy with scientific and technological innovation as the core, upgrade the production capacity of social material materials, ensure the continuous supply of material materials for life. First, we will vigorously promote the innovative spirit of market players in pursuit of excellence and give full play to the craftsmanship spirit of market players in striving for excellence. Now, with China's economic and social development and the well-being of the past ever more needs for science and technology solutions, is the first motive force, more need to increase the innovation in the fierce international competition in front, in unilateralism, under the background of rising protectionism ( $\mathrm{Li} \& \mathrm{Yu}, 2021$ ), the need to highlight the original innovation ability in the position. Secondly, we should adhere to problem orientation and strengthen the dominant position of enterprise innovation. Government in the support of scientific research funds, and the preferential tax policy level, should give support of innovative enterprises, provide good policy law space for the innovation of the enterprise (Zou \& Long, 2021), build the market environment to encourage innovation, encourage enterprises to develop the use of advanced technology, promoting the transformation of scientific and technological achievements into real social productivity.Finally, market entities continue to strengthen international scientific and technological exchanges and cooperation with other economies in the world, actively introduce advanced technologies from other countries in the production factor market, learn excellent and advanced market economy management experience, and actively import highquality products produced by enterprises into the international market under the condition of market opening.

\subsection{In Terms of Regional Cooperation and Development: Coordinate Regional Development Internally, and Integrate into the Global Economy Comprehensively and Intensely Externally}

On the one hand, the domestic grand circulation is the main body of the new development pattern of "double circulation", which also enlightens us that to realize the domestic grand circulation, we must base on the actual problems in China at present, and coordinate the development between the urban and rural areas, and between the eastern, central and western geographical spaces. Among them, the implementation of urban and rural regional economy circulation is an 
important aspect of domestic large cycle, at present, China is in rapid development period of urbanization, the process is to create huge market demand, and increase effective market supply, meet the market consumption, must make full use of the domestic factor market, domestic products market, optimizing the resources distribution of two different markets, Should give play to the role of central cities and urban agglomeration, the implementation of the strategy for the regional major construction of modern city circle, forming a batch of new growth pole, and actively implement the strategy of rejuvenating the country, promote rural economic development, at the same time to ensure the material supplies for the development of rural economy and technical support, encourage outstanding university graduates to work in rural areas, Encourage migrant workers to return to rural areas and start businesses locally, so as to provide labor support for the sustainable development of rural economy. On the other hand, the international double circulation has played a mutually reinforcing role in the domestic cycle. Therefore, the external all-around deep integration into the global economy is the inevitable requirement to promote the international great cycle. In the international market, we will actively create a fairer market environment, attract investment from other countries at a higher level, and bring high-quality investment into the international market for factors of production

\subsection{Industrial Structure Optimization and Upgrading: Focus on Optimizing the Supply-Side Structural Reform, and Strive to Achieve a Benign Interaction between Supply and Demand}

Economic circulation is the circulation and circulation of economic elements in production, circulation, distribution, consumption and other links. To ensure that this cycle is unimpeded, we must first focus on optimizing the supply-side structural reform, activating a wide range of demand with high-quality supply, and breaking down industrial barriers, regional barriers and domain barriers on the basis of getting through both ends of supply and demand (Yang, 2021). To optimize supply-side structural reform, priority should be given to transforming traditional industries, vigorously developing strategic emerging industries, and accelerating the development of modern service industries. Second, we need to accelerate the development of a complete system of domestic demand, upgrade the policy support system for expanding domestic demand, and give full play to the fundamental role of consumption in promoting the development of the domestic and international market economy. By optimizing the tax system of value-added tax and consumption tax, consumption potential can be effectively stimulated and consumption upgrading can be promoted ( $\mathrm{Li}$, Zhang, \& Xu, 2021). At the same time, we should play the key role of investment in optimizing the supply structure in both the domestic and international markets, actively strengthen economic cooperation with different economies, expand the space for investment, and optimize the investment structure. Finally, build a new pattern of "binary" development needs to promote win-win cooperation and open sys- 
tem, and the rest of the world economy on goods, services, import and export trade between international macroeconomic policy coordination, realize the industrial structure between various economies in the international circulation of complementary advantages, actively promote the construction of an open world economy, Strive to achieve an overall balance between supply and demand in the world market.

\section{Conclusion}

Based on the Marxist theory of political economy, this study discusses in detail the theoretical logic and specific implementation path of China's new development pattern of constructing the domestic great cycle as the main body and mutually promoting the domestic and international double circulations. First, this paper puts forward complete contradiction movement in the process of social production is a new development pattern of "binary" theoretical basis, establish a new development pattern of "binary" rely on "factor market", "product marketing", need to make full use of the domestic market on the basis of expanding the international market "market space, to fully respect and play to the role of the law of value, We will strengthen the government's function of macro-economic policy regulation. Secondly, according to the principle of the unity of productive forces and production relations, economic foundation and superstructure in Marxist political economy, this paper analyzes the constraint conditions of constructing the new development pattern of "double circulations" from four dimensions, namely, economic system, innovation ability of market subjects, regional location and industrial structure. Finally, the paper puts forward the specific implementation path of the new development pattern from four aspects: top-level design of economic system, cultivation of innovation ability of market subjects, regional and regional cooperation and development, and optimization and upgrading of industrial structure.

The shortcomings of this paper are as follows: Firstly, in terms of research methods, descriptive analysis is mainly adopted for research questions without objective economic data as the support for the research questions; Secondly, at the level of reference research materials, this paper integrates the existing domestic literature research materials, but does not refer to the research literature materials of foreign scholars. Finally, at the research conclusion level, the implementation path of the new development pattern of "Double circulation" needs to be further tested. In order to better study this topic, it needs to be repeatedly demonstrated in practice.

\section{Conflicts of Interest}

The author declares no conflicts of interest regarding the publication of this paper.

\section{References}

Cheng, E. F., \& Zhang, F. (2021). Political Economy Analysis of the New Development 
Pattern of "Double Circulation". Probe, No. 1, 108-115.

Li, Q., \& Yu, Q. S. (2021). New Development Stage and New Development Pattern Construction. Journal of Fujian Normal University (Philosophy and Social Sciences Edition), No. 3, 30-45.

Li, X. H., Zhang, C. F., \& Xu, S. Y. (2021). Fiscal and Tax Policy Development Path Selection under the Double-Circular New Development Pattern. Financial Supervision, No. 12, 5-10.

Lin, Y. L. (2021). Political Economy Reflection on Constructing New Development Pattern. Journal of Shanxi Provincial Party Committee of the Communist Party of China, 44, 60-64.

Wang, H. J., \& Qi, X. L. (2021). Political Economy Logic and Realization Path of the New Development Pattern of "Double Circulation". Contemporary Economic Research Journal, No. 5, 28-38, 113.

Wang, W. P., \& Niu, X. X. (2021). On the Benign Interaction between the New Development Pattern of "Double Circulation" and the High-Quality Development of Economy. Economist, No. 6, 5-12.

Wu, S. L. (2020). The Strategic Meaning of the New Development Pattern of "Double Circulation". Quisition, No. 6, 90-99.

Yang, L. (2021). Study on the Internal Logic and Practical Path of the New Development Pattern of "Double Circulation". Hunan Social Sciences, No. 3, 98-104.

Zou, X. Y., \& Long, X. L. (2021). Thinking on the Effective Path of Constructing the New Development Pattern of "Double Circulation". Consumption Daily, No. 3, 6-25. 